\title{
MULTI-CRITERIA DECISION ANALYSIS OF ENTREPRENEURIAL ORIENTATION AND BUSINESS PERFORMANCE IN NIGERIA
}

\section{Sulaimon Olanrewaju ADEBIYI ${ }^{1}$, Bilqis Bolanle AMOLE ${ }^{2}$, Kareem Abidemi ARIKEWUYO $^{3}$, Olamilekan Gbenga OYENUGA ${ }^{4}$}

${ }^{1,2,4}$ University of Lagos, Akoka, Nigeria

${ }^{3}$ Kwara State University, Molete, Nigeria

Corresponding author's e-mail: lanre18april@gmail.com

\begin{abstract}
This study advances research on entrepreneurial orientation and business performance by assessing, prioritizing, ranking, and evaluating decision choices among entrepreneurial orientation attributes that influence small and medium scale enterprise performance in Nigeria. Data were gathered through the multi-criteria decision-making (MCDM) tool called analytic hierarchy process (AHP) based questionnaire administered to practicing entrepreneurs in Lagos State, Nigeria. The population of the study consists of all the firms (mainly small and medium scale businesses) registered by Lagos Chamber of Commerce, totalling 1766 at the time of this study. The sample size was calculated through Yamane formula, while entrepreneurs managing the sampled firms were the respondents carefully selected for the study through a random sampling procedure. Data collected were analysed through descriptive statistics and analytic hierarchy process procedures for eliciting the consistency ratio, consistency index, Lambda Max, local and global priority values for an effective policy decision. The priorities were established in line with the AHP framework using pairwise comparisons and judgment of entrepreneurs. The results revealed the preference of entrepreneurial orientation dimension that influenced business performance most based on pairwise experiences and trade-off of different attributes. This study explores the application of AHP methodology for measuring complex entrepreneurial decision-making process for enhancing business performance. Thus, the AHP revealed a potential research method in computing weights and chasing MCDM process.
\end{abstract}

Keywords: Analytic Hierarchy Process, Business performance, Entrepreneur, Entrepreneurial orientation, MCDM.

JEL Codes: B16, M1, M21, O31

\section{INTRODUCTION}

In this information age of the $21^{\text {st }}$ century, where decision-making is fundamentally complex and multifaceted, many factors and forces operating in the business environment continue to exert significant influence on the decision maker and its environment. All the relevant factors and forces need to be weighted against other contending priorities since every change in the business environment will either close some old opportunities or open new ones. The multi-criteria analysis is 
then more needful than before by decision-maker/entrepreneurs to be able to choose the best decision that gives optimum and satisfying results for the benefits of the stakeholders. Analytic Hierarchy Process is one of the modern tools developed 40 years ago but constantly improved in order to assess, prioritize, rank and evaluate decision choices (Saaty, 1999).

Entrepreneurial orientation (EO) can be explained as the company strategic orientation in order to acquire specific entrepreneurial aspects of decision-making styles, practices and methods, which enables small firms or new ventures to perform better than their competitors and enhances firm performance (Radipere, 2014; Wiklund \& Shepherd, 2005). Thus, understanding the impacts of entrepreneurial orientation dimensions on small business performance especially in developing countries like Nigeria where small businesses dominate the economic environment is something that stimulates the interest of many researchers and practitioners over time. It is through having a proper assortment of the entrepreneurial orientation dimension in terms of linking the priority to decisions that can bring about optimum benefits for sustainable small business development.

According to Andendorff (2004), entrepreneurial orientation is about the extent to which management and owners of the business are motivated to taking businessrelated risks to support changes and innovation in order to obtain a competitive advantage for the business. For a turbulence business environment like in Nigeria, it is more than required but necessary that an appropriate entrepreneurial orientation is properly blended in the understanding of various influences of entrepreneurial orientation dimensions on the decision-making by business owners and managers for ensuring sustainable business performance.

Although studies on entrepreneurial orientation focused on the use of other methods aside from Multi-Criteria Decision Analysis (MCDA), this is one of a few attempts as far as research is aware to model and analyse entrepreneurial orientation dimensions and business performance for effective managerial decision-making. MCDA approaches are well suited for the study of several financial decisionmaking problems owing to the diversified nature of the factors (evaluation criteria, objectives and goals) that affect business performance positively. The complexity of the entrepreneurial orientation dimension and attributes, the dynamic nature of the business and economic environments, the subjective nature of many financial decisions are only some of the features of business performance which are in accordance with the MCDA modelling framework. On the basis of these remarks, applications of MCDA methodologies like AHP is essential in assessing, prioritizing, ranking, and evaluating decision choices among entrepreneurial orientation attributes that influence the performance of small and medium scale enterprises (SMEs) in Nigeria. This study suggests a significant AHP-based framework, which can be empirically tested in a business environment outside Nigeria and across different sectors of the economy in order to generalize the findings for sustainable entrepreneurship development.

Irrespective of the number and size of new businesses created by any entrepreneurial activities in any economy, one cannot deny a significant role played by new venture creation through job creation and fuelling of economy. Moreover, EO characteristics are very essential for SME owners and entrepreneurs in 
formulating and implementing competitive strategies necessary for surviving in a turbulent business environment like Nigeria, where the ease of doing business rank is very low compared to other countries in the world (The World Bank on the Ease of Doing Business ranks Nigeria $145^{\text {th }}$ out of 190 countries in the world). Thus, this and other strategic contributions of SMEs to any economy make study of this nature stimulating and worthwhile.

\section{LITERATURE REVIEW}

The debate in the literature on the influence of entrepreneurial dimension on business performance is mixed. While some studies find a positive influence of entrepreneurial dimension on business performance, others claim they cannot identify a positive relationship between the dependent and independent variables (Zhang \& Zhang, 2012; Wiklund, \& Shepherd, 2005; Lumpkin \& Dess, 1996). Moreover, Lumpkin \& Dess (1996) argue that the five dimensions of EO (autonomy, innovativeness, risk-taking, pro-activeness and competitiveness) might produce varying results on the business performance whenever different environment and organisational context are being considered. While different methodologies were employed in the previous study, the discipline of operation research is contributing with this study through the application of Multi-Criteria Decision-Making (MCDM) tool called Analytic Hierarchy Process (AHP) for modelling and analysing pairwise influences of EO criteria on business performance among entrepreneurs in Nigeria.

The AHP serves as a powerful tool in calculating weights of the influence of entrepreneurial dimension on business performance pursuing MCDA procedure. The AHP method was favoured for this study owing to its advantages over other multi-criteria through flexibility, intuitive appeal to the decision makers, its ability to check for inconsistencies and ability to reverse judgments where necessary. Furthermore, AHP is the most widely employed multi-criteria decision analysis technique that has produced many quality publications in various fields (Oyatoye, Adebiyi, \& Amole, 2018; Adebiyi, Oyatoye \& Kuye, 2015; Vaidya \& Kumar, 2006). Hence, it is also a method that can help capture both the subjective and objective evaluation measures of entrepreneurial orientation and business performance by reducing bias in decision-making.

On the other hand, Gautam (2016) examines the role of EOs in business performance of handicraft enterprises in Nepal. Data were sought for the five EO dimensions from 196 respondents through a simple random sample. Of the 178 returned questionnaires, only 161 were valid for the analysis. The data were analysed using descriptive statistics, correlation and regression analysis. Arief et al. (2013) assessed the effects of EO on the performance of SME cluster in Malang, using a survey approach; data were collected from 140 SMEs on the variables of interest EO and business performance, while strategic flexibility was used as a mediating variable between the independent and dependent variable. The data collated were analysed using AMOS 16 and the results revealed a direct significant effect of EO on firm performance, but better results were achieved with the mediation of strategic flexibility. The study was limited in application as only three 
out of five dimensions of EO were used and the variable was summed, which prevented exploration of pairwise comparison of individual EO dimension and business performance. This current study uses not only a different methodology (AHP), but derived priority scales that synthesise all attributes of EOs and business performance for the purpose of decision-making involving many criteria and subcriteria (alternatives).

Besides, in order to advance research in the entrepreneurial discipline, there is a need for a robust methodology like AHP, which goes beyond establishing the relationship among variables and provides a hierarchical framework for the five dimensions (see Fig. 1), as well as helps determine the local and global priorities of criteria and alternatives for a policy action that influences business performance.

\section{METHODS AND PROCEDURES}

This study adopted quantitative methods, which were generally associated with the philosophical traditions of positivism. Cross-sectional survey research was designed with a focus on entrepreneurs registered in Lagos, Nigeria. In sampling the respondents, the database (including 1766 registered businesses) of Lagos Chamber of Commerce and Industries (LCCI) was used. Using the figure as the population for the study, a simple random sample method was used through Yamane (1967) formula as given below:

$$
n=\frac{N}{\left(1+N(e)^{2}\right)},
$$

where $n$ is the sample size, $N$ is the population size (registered businesses by $\mathrm{LCCI}$ ) and $e$ is the sampling error (0.05). From the above expression, the sample size is obtained as follows:

$$
n=\frac{1766}{\left(1+1766(0.05)^{2}\right)}=326.13
$$

Thus, a total sample size of 327 entrepreneurs was sufficient for this study. The researchers administered a total of 350 copies of the research instrument in order to reduce a sampling error, minimize case of non-return of questionnaire and nonresponse bias. Simple random sampling was used and a sample of 350 decisionmakers/experts/entrepreneurs on the register of LCCI. Out of 338 questionnaires retrieved with the support of research assistants, sizable 329 copies of questionnaire were valid for the analysis, which represented an effective response rate of 94 percent. The data collected were analysed through pairwise comparison of the criteria and their alternatives. A decision-making model was designed with 5 criteria, 27 sub-criteria, which equally served as the alternatives for the three-level hierarchical model. The model was developed with the successful entrepreneurs who served as experts in evaluating relevance of the criteria and alternatives as elicited from literature in their own business environment and presented in Figure 1. 


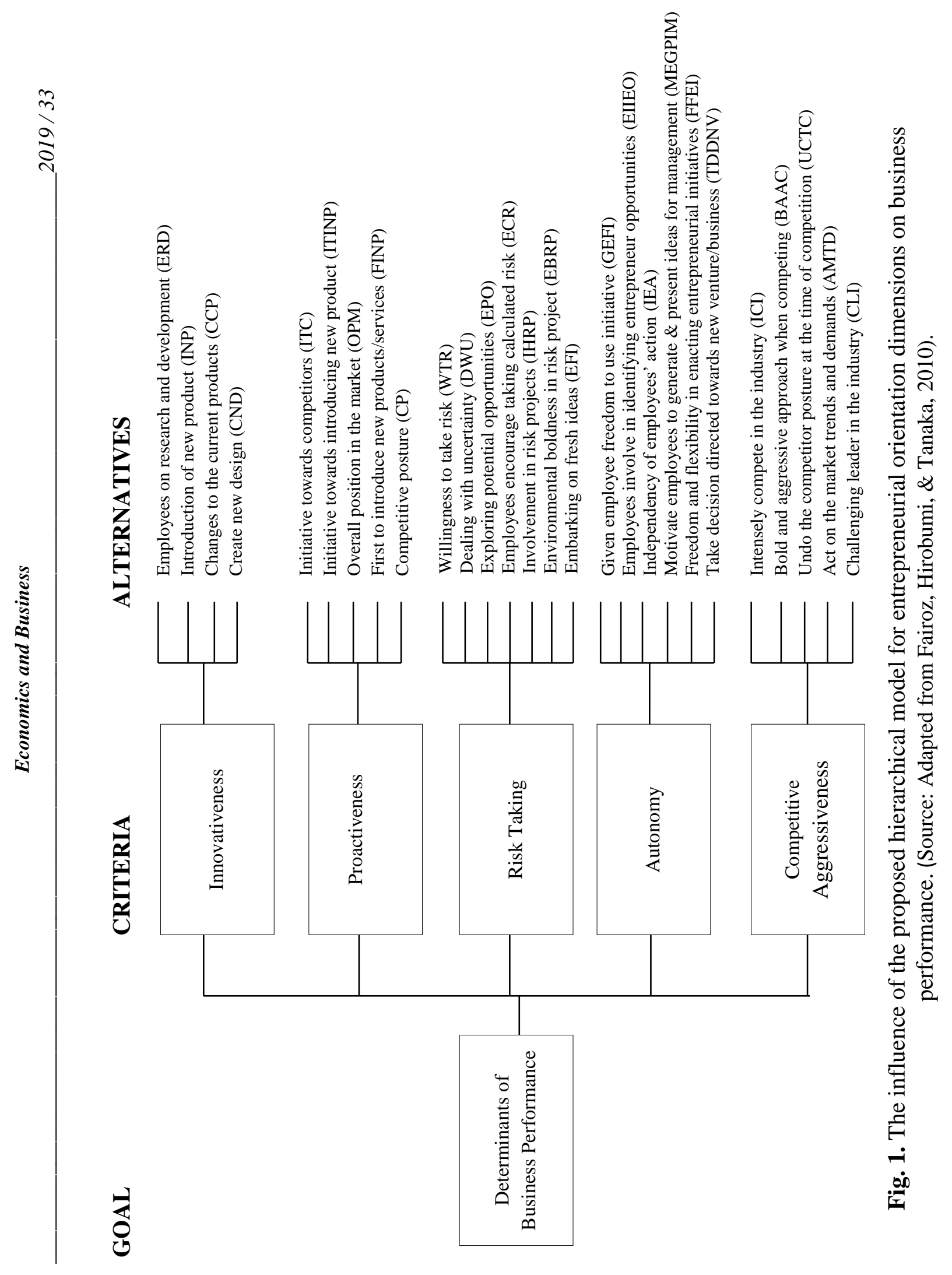




\section{RESULTS AND DISCUSSION}

The data collected through entrepreneurs regarding the influence of the five dimensions on business performance were analysed following the analytical hierarchy process methodology. Since the goal of the hierarchical structure was to evaluate the influence of EO dimension on business performance, the EO dimensions (Innovativeness, Proactiveness, Risk Taking, Autonomy and Competitive Aggressiveness) served as criteria for pairwise comparison. The dimensions were paired with respect to their common relative influence on performance and then compared. Therefore, pairwise comparisons were constructed.

Furthermore, the eigenvalue method was used to estimate the weights of decision elements (EO dimensions), while the consistency of the judgment was checked by computing the Consistency Index $(C I)$ and Consistency Ratio $(C R)$ from the total of 1974 comparison matrices constructed using the responses of 329 retrieved and valid questionnaires. The AHP analysis of respondents' comparison matrices of the criteria with respect to the main goal, which was the determinant of business performance based on the entrepreneurial orientation dimension and subcriteria with respect to each criterion, was reduced to one matrix for each level of the hierarchy. Therefore, 1974 matrices were analysed individually and they were reduced to six (6) comparison matrices using 1/329 ratio (see Table 1 as an example).

Table 1. Reduced Matrix for Determinant of Business Performance

\begin{tabular}{|l|l|l|l|l|l|l|}
\hline $\begin{array}{c}\text { Business } \\
\text { Performance }\end{array}$ & $\begin{array}{c}\text { Innovati- } \\
\text { veness }\end{array}$ & $\begin{array}{c}\text { Proacti- } \\
\text { veness }\end{array}$ & $\begin{array}{c}\text { Risk } \\
\text { Taking }\end{array}$ & Autonomy & $\begin{array}{c}\text { Competitive } \\
\text { Aggressiveness }\end{array}$ & $\begin{array}{c}\text { Priority } \\
\text { Vector }\end{array}$ \\
\hline Innovativeness & 1.0000 & 0.1626 & 0.1604 & 0.1610 & 1.0000 & 0.1117 \\
\hline Proactiveness & 1.4079 & 1.0000 & 0.3504 & 0.6667 & 0.3709 & 0.1211 \\
\hline Risk Taking & 1.9783 & 2.8536 & 1.0000 & 0.1714 & 0.2667 & 0.1793 \\
\hline Autonomy & 1.7519 & 1.5000 & 1.3236 & 1.0000 & 0.2263 & 0.1728 \\
\hline $\begin{array}{l}\text { Competitive } \\
\text { Aggressiveness }\end{array}$ & 1.0000 & 2.6959 & 3.7500 & 4.4195 & 1.0000 & 0.4151 \\
\hline
\end{tabular}

The last column of Table 1 is denoted by weight, which is also known as eigenvector. These values in the column have a direct physical meaning in AHP. The values determine the participation or weight of those criteria relative to the total results of the goal. Based on the determinant of business performance among these entrepreneurial orientation factors stated, competitive aggressiveness criterion has a weight of $41.51 \%$ relative to the total goal. A positive evaluation of this factor contributes four times more than a positive evaluation of the innovativeness criterion $(11.17 \%)$. Following the procedure of AHP, there was a need to check for data inconsistencies. The main objective was to capture enough information to determine whether the respondents were consistent in their choices. The inconsistency index is based on maximum lambda which is calculated by summing 
the product of each element in the eigenvector (weight) by the respective column total of the original comparison matrix. Table 2 below demonstrates the calculation of the maximum eigenvalue, which is also called maximum lambda denoted as $\lambda_{\max }$.

Table 2. Calculation of the Maximum Eigenvalue of the Five Criteria with Respect to Goal which States the Determinant of Entrepreneurial Orientation

\begin{tabular}{|l|l|l|l|l|l|}
\hline \multicolumn{1}{|c|}{ Criteria } & Innovativeness & Proactiveness & $\begin{array}{c}\text { Risk } \\
\text { Taking }\end{array}$ & Autonomy & $\begin{array}{c}\text { Competitiveness } \\
\text { Aggressiveness }\end{array}$ \\
\hline $\begin{array}{l}\text { Eigenvector } \\
\text { /weight }\end{array}$ & 0.1117 & 0.1211 & 0.1793 & 0.1728 & 0.4151 \\
\hline Total sum & 7.1380 & 8.2121 & 6.5845 & 6.4186 & 2.8639 \\
\hline $\begin{array}{l}\text { Maximum } \\
\text { eigenvalue } \\
\left(\lambda_{\max }\right)\end{array}$ & $\begin{array}{l}(0.1117 \cdot 7.1380)+(0.1211 \cdot 8.2121)+(0.1793 \cdot 6.5845)+(0.1728 \cdot 6.4186)+ \\
(0.4151 \cdot 2.8639)=(0.7973+0.9944+1.1806+1.1091+1.1888)=5.2702\end{array}$ \\
\hline
\end{tabular}

The test of consistency is derived from this formula

$$
C I=\left(\lambda_{\max }-n\right) /(n-1)=(5.2702-5) /(5-1)=0.2702 / 4=0.0676
$$

In order to validate the consistency index, consistency ratio is prescribed, which is determined by dividing the consistency index by random index $(R I)$. The matrix is considered consistent if the value obtained is less than $10 \%$. The random index is always fixed based on the number of the evaluated criteria. In this scenario of determinant of business performance, the consistency ratio of the initial group criteria is as follows:

$$
C R=C I / R I=0.0676 / 1.12=0.0603
$$

Since the value derived is less than $10 \%$, the matrix is considered consistent.

Therefore, based on the priority weight / eigenvector of the determinant of business performance criteria, it is evident that a competitive aggressiveness criterion has contributed to a weight of $41.51 \%$ to the main goal, while the innovativeness criterion has the least contribution of approximately $11.17 \%$ in relation to the goal, which states that as determinants of business performance, being competitive aggressive as a firm/an entrepreneur is more influential in aiding business performance.

Consequently, this procedure is followed in computing the relationship among the alternatives and the criteria with respect to business performance. Hence, the Table 3 below depicts individual local weight of the entrepreneurial orientation criteria and the local weight of the decision alternatives with regards to the entrepreneurial orientation criteria, which determine the performance of businesses in Nigeria. These local weights of the decision criteria and alternatives were multiplied together to arrive at the global weight as shown in the last column of the table. 
Table 3. Tabular Presentation of the Decision Criteria and Alternatives with their Priority

\begin{tabular}{|c|c|c|c|c|}
\hline Criteria & $\begin{array}{c}\text { Local } \\
\text { weight }\end{array}$ & Alternatives & $\begin{array}{c}\text { Local } \\
\text { priority }\end{array}$ & $\begin{array}{l}\text { Global } \\
\text { weight }\end{array}$ \\
\hline \multirow[t]{4}{*}{ Innovativeness } & \multirow[t]{4}{*}{0.1117} & $\begin{array}{l}\text { Emphasis on research and } \\
\text { development }\end{array}$ & 0.1403 & 0.0157 \\
\hline & & Introduction to new products & 0.3288 & 0.0367 \\
\hline & & Changes to current products & 0.3772 & 0.0421 \\
\hline & & Create new design & 0.1537 & 0.0172 \\
\hline \multirow[t]{5}{*}{ Proactiveness } & \multirow[t]{5}{*}{0.1211} & Initiative towards competitors & 0.2072 & 0.0251 \\
\hline & & $\begin{array}{l}\text { Initiative towards introducing new } \\
\text { products }\end{array}$ & 0.1651 & 0.0200 \\
\hline & & Overall position in the market & 0.1830 & 0.0222 \\
\hline & & $\begin{array}{l}\text { First to introduce new product } \\
\text { services than competitors }\end{array}$ & 0.1899 & 0.0230 \\
\hline & & Competitive posture & 0.2548 & 0.0309 \\
\hline \multirow[t]{7}{*}{ Risk Taking } & \multirow[t]{7}{*}{0.1793} & Willingness to take risk & 0.1190 & 0.0213 \\
\hline & & Dealing with uncertainty & 0.0814 & 0.0146 \\
\hline & & Exploring potential opportunities & 0.1141 & 0.0205 \\
\hline & & $\begin{array}{l}\text { Encourage calculated risk with } \\
\text { new idea }\end{array}$ & 0.1563 & 0.0280 \\
\hline & & Involvement in high risk projects & 0.1660 & 0.0298 \\
\hline & & Environmental boldness & 0.1366 & 0.0245 \\
\hline & & Embarking on fresh projects & 0.2266 & 0.0406 \\
\hline \multirow[t]{6}{*}{ Autonomy } & \multirow[t]{6}{*}{0.1728} & $\begin{array}{l}\text { Given employees freedom to use } \\
\text { initiative }\end{array}$ & 0.1205 & 0.0208 \\
\hline & & $\begin{array}{l}\text { Employee identifying } \\
\text { entrepreneur opportunities }\end{array}$ & 0.1671 & 0.0289 \\
\hline & & Independency of employee action & 0.1115 & 0.0193 \\
\hline & & 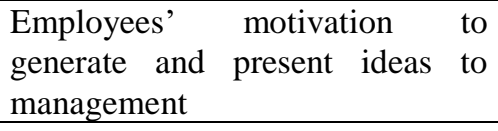 & 0.2067 & 0.0357 \\
\hline & & $\begin{array}{l}\text { Freedom flexibility in } \\
\text { entrepreneurial initiative }\end{array}$ & 0.2028 & 0.0350 \\
\hline & & $\begin{array}{l}\text { Take decision directed towards } \\
\text { new product }\end{array}$ & 0.1914 & 0.0331 \\
\hline \multirow{5}{*}{$\begin{array}{l}\text { Competitiveness } \\
\text { Aggressiveness }\end{array}$} & \multirow[t]{5}{*}{0.4151} & Intensely compete in the industry & 0.1379 & 0.0572 \\
\hline & & $\begin{array}{l}\text { Bold and aggressive approach } \\
\text { when competing }\end{array}$ & 0.2035 & 0.0845 \\
\hline & & $\begin{array}{l}\text { Undo the competitor posture at the } \\
\text { time of competition }\end{array}$ & 0.2534 & 0.1052 \\
\hline & & $\begin{array}{l}\text { Act on the market trends and } \\
\text { demands }\end{array}$ & 0.2432 & 0.1010 \\
\hline & & Challenging leader in the industry & 0.1620 & 0.0672 \\
\hline
\end{tabular}

From Table 3, findings depicted significant relationships between EO variables and business performance of SMEs in Nigeria at varying magnitude. Among the EO measuring items, competitive aggressiveness was found strongly influential on 
the growth of SME performance in Nigeria. This implies that a continuous increase in competitive aggressiveness activities tend to aid more progressive business performance for SMEs within the nation. Thus, the finding is consistent with the findings of the previous studies by Arshad, Rasli, Arshad, \& Zain (2014) and Gautam (2016), where competitive aggressiveness was found to be positively significant among technology-based SMEs, and Nepalese handicraft businesses, respectively. However, the study conducted by Musa, Ghani, \& Ahmad (2014) discovered that competitive aggressiveness depicted negative relationship with business performance. Within the competitive aggressiveness, loosening the competitors' posture during competition and usage of bold and aggressive competitive approaches were found significantly influential to SMEs in their pursuit for progressive business performance. This suggests that for entrepreneurs to boost their business performance positively, monitoring the trends in the market is not sufficient.

Considering the decision alternatives of innovativeness criterion, the weight computed demonstrated the contribution of each of the alternatives with respect to innovativeness criterion, which showed that changes to current product (CCP) contributed to $37.72 \%$ in relation to the innovativeness criterion. A positive evaluation of these factors contributed approximately three times more than the positive evaluation of emphasis on research and development (ERD) with $14.03 \%$.

Looking at the decision alternatives for proactiveness criterion, the last column indicated as weight showed that competitive posture contributed $25.48 \%$ to the proactiveness criterion, which was followed by initiatives towards competitors and later being the first to introduce a new product or service with a weight of $18.99 \%$ which was closely followed by getting good overall position in the market with priority vector of $18.30 \%$ and imitativeness towards introducing the new products (ITNP) contributed $16.51 \%$ to the proactiveness criterion

Considering the alternatives of risk-taking criterion, embarking on fresh projects had the largest contribution of approximately $23 \%$ among others and dealing with uncertainty had the smallest contribution of approximately $8 \%$ which indicated that embarking on fresh project contributed approximately three times more than dealing with uncertainty criterion.

From the reduced matrix of autonomy alternatives, it is observed from the last column denoted as weight that motivating employee to generate and present new idea to management contributed very closed to $21 \%$ to the autonomy criteria and the independency of the employee's action as the least contribution. This shows that motivating employee to generate and present new idea contributed twice more than the independency of employees' action.

Looking at the competitive aggressiveness alternatives, it is seen that entrepreneur's needs to undo competitor posture at the time of competition takes one-quarter of drives for competitive aggressiveness dimension of entrepreneurial orientation. This was followed by the ability to act on the market demands and trends with weight of $24.32 \%$.

Additionally, the study found other EO dimensions to be weak indicators of business performance among SMEs in Nigeria. Therefore, the need for strategic planning and repositioning seems paramount because they exhibit a positive 
relationship with business performance. However, previous studies conducted by Haider, Asad, \& Fatima (2016) and Arshad et al. (2014) depicted a positive and significant relationship between EO dimensions and business performance, but autonomy was found to be negatively correlated to business performance (Arshad et al., 2014). Moreover, Anlesinya, Eshun, \& Bonuedi (2015) discovered proactiveness and risk taking to be positively significant to profitability while innovativeness exhibited no relationship with profitability. In addition, among the five EO dimensions only innovativeness and proactiveness were found to be significant and positive related to cooperative firm business performance in Malaysia (Musa et al., 2014).

\section{CONCLUSION AND RECOMMENDATIONS}

This paper explored the use of one multi-criteria decision-making method named Analytical Hierarchy Process to evaluate the entrepreneurial factors as determinants for business performance in Nigeria. These factors were identified from literature and pairwise comparison was made on the basis of Saaty's scale. The result of the AHP revealed that among the entrepreneurial orientation factors/criteria, competitive aggressiveness had the greatest influence on the performance of businesses with an indication that loosening the competitive posture of competitors at the time of competition in comparison with intense competition with the industry leader followed by risk taking criterion, which suggested embarking on fresh projects compared to dealing with uncertainty. Another factor was an autonomy criterion which connoted the relevance of motivating employees to generate and present new ideas to the management in relation to the independency of the employees' action. Proactiveness criterion had lesser influence on the performance of businesses and innovativeness had the least influence among these entrepreneurial orientation factors on the performance of businesses. Ranking all the decision alternatives of these entrepreneurial orientation factors/criteria, loosening the competitive posture at the time of competition was given the highest importance while dealing with uncertainty was given the least importance. Based on the observation of this analysis, there is a need for the stakeholders to look into these various factors and concentrate more on those entrepreneurial orientation factors that have lesser influence in order to have a viable and sustainable business. In addition, to improve the performance of various businesses there is a need to consider and put these strategies into practice in order to have a profitable and sustainable business venture.

\section{REFERENCES}

Adebiyi, S. O., Oyatoye, E. O. \& Kuye, O. L. (2015). An analytic hierarchy process analysis: Application to Subscriber retention decisions in the Nigerian mobile telecommunications industry. International Journal of Management and Economics, 48(1), 63-83. https://doi.org/10.1515/ijme-2015-0035

Andendorff, C. M. (2004). The development of a cultural family business model of good governance for Greek family business in South Africa. Doctoral thesis in Business Management, Rhodes University, Grahamstown. 
Anlesinya, A., Eshun, P., \& Bonuedi, A. A. (2015). Entrepreneurial orientation dimensions and profitability nexus: Evidence from micro enterprises in the retail sector in a developing Country. International Journal of Small Business and Entrepreneurship Research, 3(7), 79-87.

Arief, M., Thoyib, A., Sudiro, A. \& Rohman, F. (2013). The effect of entrepreneurial orientation on the firm performance through strategic flexibility: A study on the SMEs cluster in Malang. Journal of Management Research, 5(3), 44-62. https://doi.org/10.5296/jmr.v5i3.3339

Arshad, A. S., Rasli, A., Arshad, A. A., \& Zain, Z. M. (2014). The impact of entrepreneurial orientation on business performance: A study of technology-based SMEs in Malaysia. Procedia-social and behavioral sciences, 130, 46-53. https://doi.org/10.1016/j.sbspro.2014.04.006

Fairoz, F. M., Hirobumi, T., \& Tanaka, Y. (2010). Entrepreneurial orientation and business performance of small and medium scale enterprises of Hambantota District Sri Lanka. Asian Social Science, 6(3), 34. https://doi.org/10.5539/ass.v6n3p34

Gautam, P. R. (2016). Entrepreneurial orientation and business performance of handicraft industry: A study of Nepalese handicraft enterprises. International Journal of Small Business and Entrepreneurship Research, $4(2), 48-63$

Haider, S. H., Fatima, M., Asad, M., \& Ala'A, Z. A. A. (2016). A study on the issues of employment contracts and practices of employment contracts in UAE. Paradigms, 10(1), 58.

Lumpkin, G. T. \& Dess, G. G. (1996). Clarifying the entrepreneurial orientation construct and linking it to performance. Academy of Management Review, 21(1), 135-172. https://doi.org/10.5465/amr.1996.9602161568

Malczewski J. (2006). GIS-based multi-criteria decision analysis: a survey of the literature. International $\begin{array}{lllll}\text { Journal of } & \text { Geographical }\end{array}$ https://doi.org/10.1080/13658810600661508

Musa, D., Ghani, A. A., \& Ahmad, S. (2014). Linking entrepreneurial orientation and business performance: The examination toward performance of cooperatives firms in Northern Region of Peninsular Malaysia. International Journal of Business and Technopreneurship, 4(2), 247-264.

Oyatoye, E. O., Adebiyi, S. O. \& Amole, B. B. (2018). Analytical hierarchy process for estimating Subscribers perception of brand equity dimensions on purchase decision of Nigerian mobile telecommunication services, Yugoslav Journal of Operations Research, 28(2), 275-290. https://doi.org/10.2298/YJOR171104022O

Radipere, S. (2014). The effects of entrepreneurial orientation on business performance. Mediterranean Journal of Social Sciences, 5(16), 141-152. https://doi.org/10.5901/mjss.2014.v5n16p141

Saaty, T. L. (1999). Decision Making for Leaders, 3rd ed., RWS Publications: Pittsburgh, PA.

Wiklund, J. \& Shepherd, D. (2005). Entrepreneurial orientation and small business performance: A configurational approach. Journal of Business Venturing, 20(1), 71-91. https://doi.org/10.1016/j.jbusvent.2004.01.001

Yamane, T. (1967). Statistics, an introductory analysis, (2nd ed.). New York: Harper and Row.

Zhang, Y. \& Zhang, X. (2012). The effect of entrepreneurial orientation on business performance: A role of network capabilities in China. Journal of Chinese Entrepreneurship 4(2), 132-142. https://doi.org/10.1108/17561391211242744

\section{AUTHORS' SHORT BIOGRAPHIES}

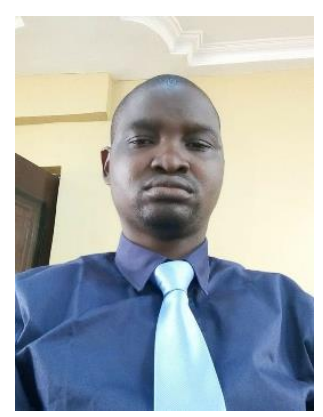

Dr. Sulaimon Olanrewaju ADEBIYI is a Lecturer at the Department of Business Administration, University of Lagos, Nigeria. He graduated with B. Sc. (Hons) Second Class Upper Division in Business Administration from Olabisi Onabanjo University, Ago Iwoye, Nigeria in 2007, bagged his M. Sc. in Operations Research from University of Lagos, Nigeria in 2010. He equally holds Master of Business Administration (MBA) with distinction from Obafemi Awolowo University, Ile-Ife, Nigeria in 2012 and was awarded Doctor of Philosophy degree (Ph. D.) in Business Administration specialising in Operations Research from the University of Lagos, Nigeria in 2015. Dr. Adebiyi's areas of research are: studies that offer contemporary solutions to challenges and discovery of new ideas and innovative approach in business/organisations, scientific research enquiry and related research. He has worked on a couple of research surveys, used operation research models and most of his works were peer reviewed and published in high rated journals.

Email: lanre18april@gmail.com

ORCID ID: https://orcid.org/0000-0001-7657-1182 


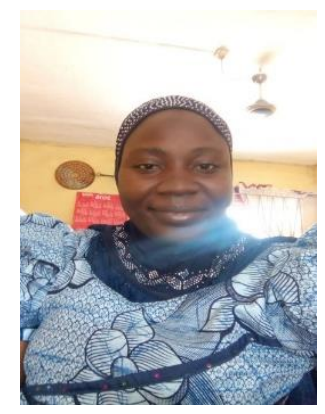

Dr. Bilqis Bolanle AMOLE is a Lecturer at the Department of Accounting and Business Administration, Distance Learning Institute, University of Lagos. She is an Operations Research specialist with focus on mathematical programming techniques, multi-criteria decision making methods in solving business problems, as well as improving business management pedagogies. She obtained her B.Sc. (Hons) Economics from Olabisi Onanbanjo University, Ago Iwoye in 2008; M. Sc. Business Administration (Operations Research), University of Lagos in 2010; Master of Business Administration (MBA) from Obafemi Awolowo University, Ile-Ife in 2012; and obtained a $\mathrm{Ph}$. D. in Business Administration from the University of Lagos in 2015. She has five years of working experience at the University of Lagos with about 20 articles published in reputable journals.

Email: bamole@unilag.edu.ng

ORCID ID: https://orcid.org/0000-0001-7143-893X

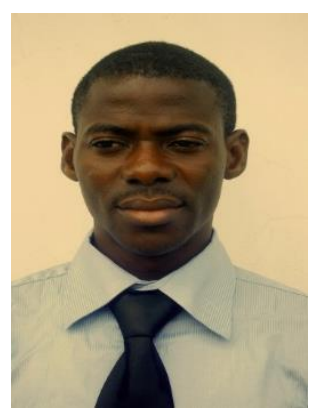

Dr. Kareem Abidemi ARIKEWUYO is a graduate of Ogun State University (now Olabisi Onabanjo University), Ago Iwoye, Nigeria where he bagged his Diploma in Marketing, B.Sc. (Banking \& Finance), M. Sc. and Ph. D. in Business \& Applied Economics (Finance Option).

As a young scholar, he began his academic journey as a Research Assistant to the Faculty of Management Sciences before he later became an Associate Lecturer at the Department of Banking \& Finance, Olabisi Onabanjo University, Ago Iwoye; Tai Solarin University of Education, Ijebu - Ode and Fountain University, Osogbo, Nigeria.

He was a pioneer coordinator of Banking \& Finance Programme at the Department of Economics \& Financial Studies, Fountain University, Nigeria. Dr. Arikewuyo is presently a Lecturer at the Department of Accounting \& Finance, Kwara State University, Malete, Nigeria. He is a Graduate Member of the Nigerian Institute of Management.

Email: abeesyou@gmail.com

ORCID ID: https://orcid.org/0000-0002-0439-8859

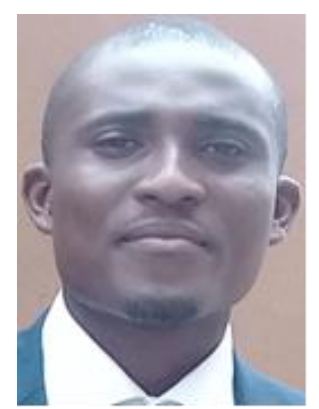

Olamilekan Gbenga OYENUGA is an aspiring specialist in Operations Research who bagged his undergraduate degree in Business Administration from the University of Lagos in 2014, and Master degree in Operations Research from the University of Lagos in 2019. In support of this, he has conducted research on organisational citizenship behaviour; knowledge sharing and analytical network process; and knowledge sharing limitations. $\mathrm{He}$ is an associate member of the International Strategic Management Institute, Nigeria.

Email: oyenuga_olamilekan@yahoo.com

ORCID ID: https://orcid.org/0000-0002-5433-6461 